\title{
Comparison between classical 'P\&O' algorithm and FLC of MPPT for GPV under partial shading
}

\author{
Youcef Abdelaziz, Bouanane Abdelkrim, Merah Abdelkader \\ L.G.E Laboratory, Departement of Electrical Engineering, Dr. Moulay Taher University of Saida, Algeria
}

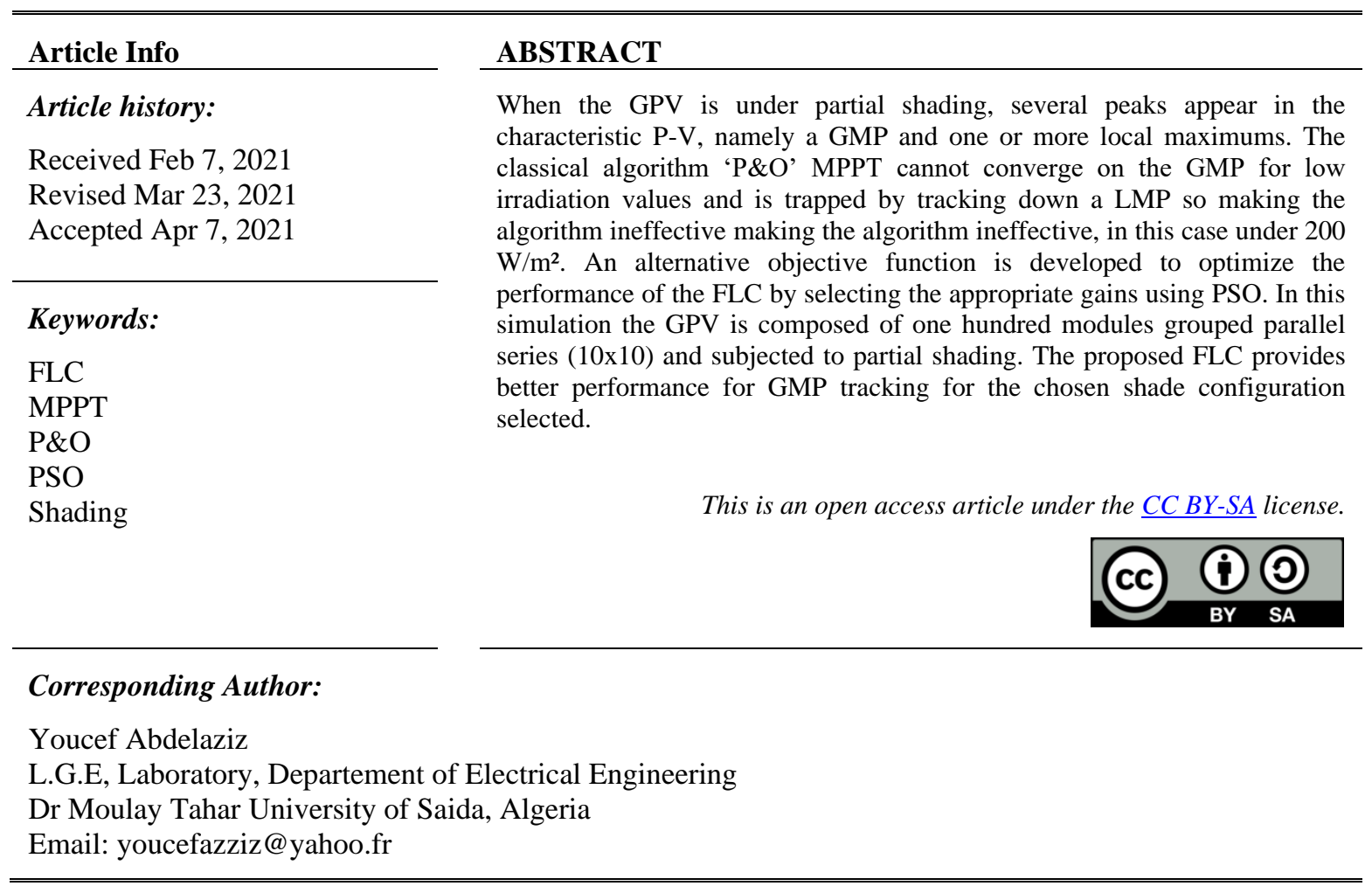

\section{INTRODUCTION}

The use of renawble energy has become a major necessity for the future of our planet. The MPPT becomes complex when the photovoltaic generator is in the presence partial shading. The research was directed towards optimizing the performance of a solar photovoltaic system by extracting its maximum power for all atmospheric conditions. The GPV is formed by a series/parallel combination of photovoltaic modules to converge on the desired GMP. Several MPPT algorithms have been proposed by researchers [1][9], the most used are: Perturb and Observe, Incremental Conductance, Constant Voltage. These methods are based on finding the maximum of the carateristic P-V of the PV solar system and are effective only when the curve has only one maximum. When passing cloudy or obstacle on a GPV, multiple points appear on the power-tension characteristic with an overall GMP maximum and LMP points. Conventional methods do not converge on the desired GMP [10]-[13].

\section{SIMULATION OF A GPV UNDER PARTIAL SHADING}

Partial shading has a major malfunction of a GPV under better conditions. Recent studies were interested in the effect of partial shading on the energy efficiency of a GPV and its impact on the functioning of the photovoltaic system to be studied [17], [18]. This phenomenon has pushed researchers [19]-[24] to use methods and algorithms to maximize power delivered by the GPV. In our previous work [25] using the classical 'P\&O' alogrithm for rechrche of the MPPT of a photovoltaic generator under partial shading for different irradiation values and a constant temperature for a configuration of one hundred series/parallel photovoltaic modules divided into three groups (G1 to G3) each subjected to different shade levels in 
Figure 1. We found that this approach to the 'P\&O' algorithm leads to an error in tracking the global power point when it changes position from Pm3 to Pm2 for values under $200 \mathrm{~W} / \mathrm{m}^{2}$ in figure 2 . The special categorization and terminology given by [26] is used for this purpose. Figure 1 shows a GPV composed of 100 modules in a mixed group $(10 \times 10)$.

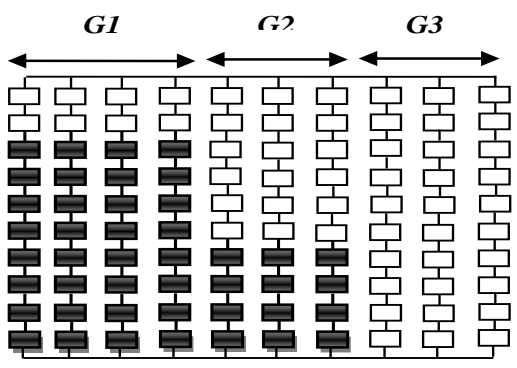

Figure 1. GPV (10x10) under parial shading divided into three groups

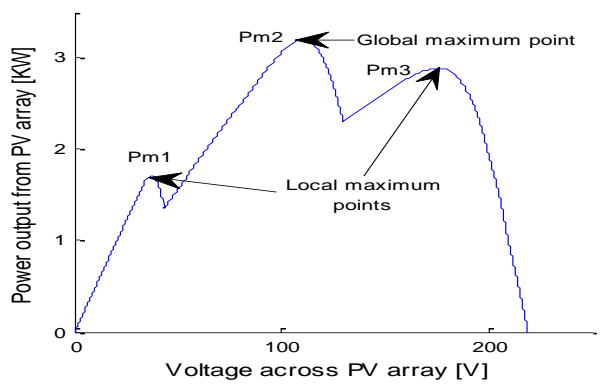

Figure 2. P-V curve of GPV under partial shading of Figure 1

The I-V characteristic of the PV module is then given by [18].

$$
I=I_{s c}-I_{0}\left(e^{\frac{V+N_{s} R_{s} I}{n V_{t} N_{s}}}-1\right)-\frac{V+N_{s} R_{s} I}{N_{s} R_{p}}
$$

From the (01) We can define the function.

$$
f(V, I, G)=I-\frac{I_{s c_{-} s t d}}{G}+I_{0}\left(e^{\frac{V+N_{s} R_{s} I}{n V_{t} N_{s}}}-1\right)+\frac{V+N_{s} R_{s} I}{N_{s} R_{p}}
$$

\section{RESULTS AND DISCUSSION}

This simulation was made for the configuration of Figure 1. The non-shaded modules receive irradiation level of $\mathrm{G}=1 \mathrm{~kW} / \mathrm{m}^{2}$. The shaded modules are under $\mathrm{G}=0.1 \mathrm{~kW} / \mathrm{m}^{2}$. The characteristic $\mathrm{P}-\mathrm{V}$ illustrates the presence of three peaks with a single GMP and two local maximums in Figure 2. Figure 3 brings together all the $\mathrm{P}-\mathrm{V}$ curves for different irradiations changes in steps of $0.1 \mathrm{~kW} / \mathrm{m}^{2}$ and a constant temperature $\mathrm{T}=25^{\circ} \mathrm{C}$ of the Figure 1. From the simulation of Figure 3, the power increases as the irradiation increases. We also note the change in the position of the GMP from Pm3 to Pm2 for low irradiation values. Table 1 shows the effect of partial shading on the 'P\&O' MPPT algorithm for a grid of values of G. It gives the 'P\&O' tracked power and the maximum available power.

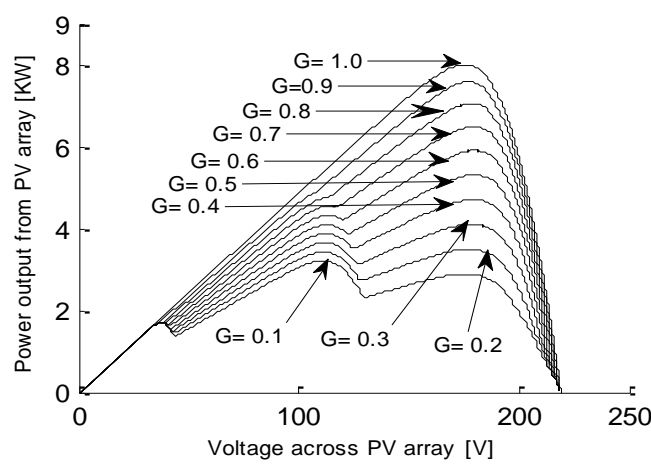

Figure 3. GPV under partial shading given by Figure 1 for different shading irradiation levels 
Figure 3 shows that for a sudden change in irradiation for shaded modules of 1000 to 50 and 100 $\mathrm{W} / \mathrm{m}^{2}$, the classical "P\&O" algorithm does not have the intelligence to converge the GMP. In this case the power losses are $08,24 \%$ and $08.99 \%$. Figure 4 shows that for a sudden change in the shading irradiation level (from 1000 to $100 \mathrm{~W} / \mathrm{m}^{2}$ ), the MPP tracked value using the P\&O algorithm converges to $2886 \mathrm{~W}$ and not towards the global MPP who is $3208 \mathrm{~W}$. The idea is to optimize the maximum power at the exit of the GPV, in this case GMP by inserting the FLC control whose gains are regulated by PSO in order to optimize the maximum output power of the GPV.

Table 1. The 'P\&O' algorithm Power tracking loss for different shading irradiation levels with the shading configuration of Figure 1

\begin{tabular}{llll}
\hline $\mathrm{G}$ & \multicolumn{3}{c}{ Maximum Power } \\
$\left(\mathrm{W} / \mathrm{m}^{2}\right)$ & $(\mathrm{W})$ & $\begin{array}{l}\text { Tracked } \\
\text { Power }(\mathrm{W})\end{array}$ & $\begin{array}{l}\text { Power Loss } \\
(\%)\end{array}$ \\
\hline 50 & 3099 & 2587 & 08,24 \\
100 & 3208 & 2886 & 08,99 \\
200 & 3488 & 3488 & 0 \\
300 & 4093 & 4093 & 0 \\
400 & 4698 & 4698 & 0 \\
500 & 5300 & 5300 & 0 \\
600 & 5896 & 5896 & 0 \\
700 & 6480 & 6480 & 0 \\
800 & 7045 & 7045 & 0 \\
900 & 7570 & 7570 & 0 \\
1000 & 7997 & 7997 & 0 \\
\hline
\end{tabular}

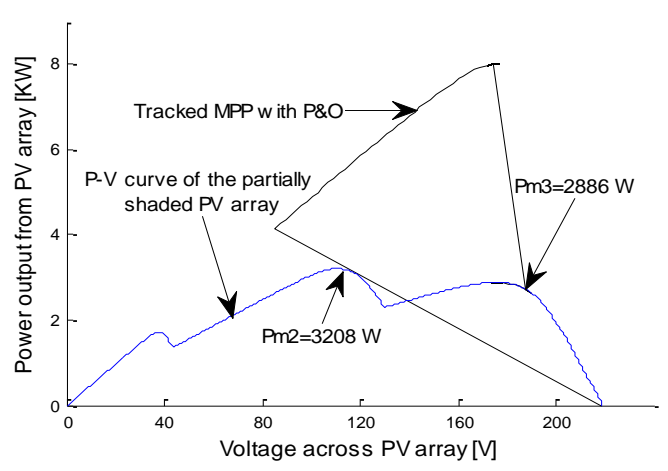

Figure 4. Classical 'P\&O' tracking process from a uniform standard irradiation to the partial shading configuration of figure 1 with a shading levelof $0.1 \mathrm{~kW} / \mathrm{m} 2$

\section{SEARCH FOR THE GMP OF A GPV UNDER PARTIAL SHADING BY THE FLC}

Explaining in this section we are going to propose a FLC command to give it the ability to track the global MPP of a partially shaded PV array. In the presence of uniform irradiation, a single GMP appears on the $\mathrm{P}-\mathrm{V}$ chacarteristic and it is easy to track it down by the classical 'P-O'. In the event of partial shading, the power output from GPV will decrease significantly and several multiple points may appear in the P-V characteristic. In this case, the P-O algorithm has not the potential to find the GMP unless the operating point does not change position. Our model is set with a limited number of rules [27]-[29]. The FLC command used in the search for the GMP performs better, namely its robustness and simplicity. The main parts of FLC, fuzzification, rule-base, inference and defuzzification, are show in Figure 5 [30]. The strategy to simulate our configuration of Figure 1 is to insert between the GPV and the load a DC-DC converter (boost) controlled by the FLC algorithm.

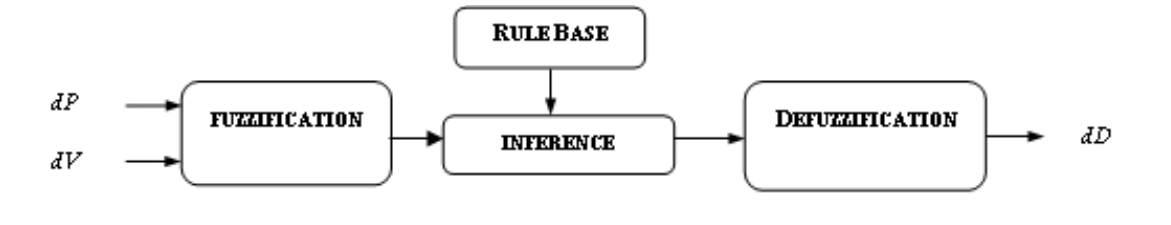

Figure 5. The FLC structure

The principle of a FLC command is based on two input variables which are the error E and the error change $\mathrm{dE}$ and an output variable $\mathrm{dD}$ (variation of the duty cycle). The value of the output variable, which drives the static converter to find the GMP, is determined using a truth table and changing input parameters. error $\mathrm{E}$ is defined as the difference between $\mathrm{dP} / \mathrm{dV}(\mathrm{k})$ and the desired value $\mathrm{dP} / \mathrm{dV}(\mathrm{k})=0$. This last value corresponds to the unique extremum of the curve $\mathrm{P}=\mathrm{f}(\mathrm{V})$. This extremum is a maximum. The more positive $\mathrm{E}$ is, the higher the value of $\mathrm{P}$. Conversely, the more negative $\mathrm{E}$ is, the lower the value of P. Finally, when $\mathrm{E}$ tends to 0 , the value of $\mathrm{P}$ tends to its maximum, the MPP. It can be likened to the slope of $\mathrm{P}=\mathrm{f}(\mathrm{V})$.

$$
E(k)=\frac{d P}{d V}(k)-0=\frac{d P}{d V}
$$


The variation in the deviation $\mathrm{dE}$ indicates in which direction and in what proportion the deviation changes as the algorithm proceeds. So, when $\mathrm{dE}$ tends to 0 , the system stabilizes. The first, second input variable and the only one output for the FLC are divided into five fuzzy sets: NB (negative big), NM (negative medium), Z (zero), PM (positive medium) and PB (positive big). The rules are formed as shown in Table 2 and Figure 7 [31].

$$
d E(k)=E(k)-E(k-1)
$$

Table 2. Fuzzy logic rules

\begin{tabular}{cc}
\hline dE/E & NG, NM, Z, PM, PBB \\
\hline NG & NG, NG, NG, NM, EZ \\
NM & NG, NG, NM, EZ, PM \\
EZ & NG, NM, EZ, PM, PG \\
PM & NM, EZ, PM, PG, PG \\
PG & EZ, PP, PG, PG, PG \\
\hline
\end{tabular}

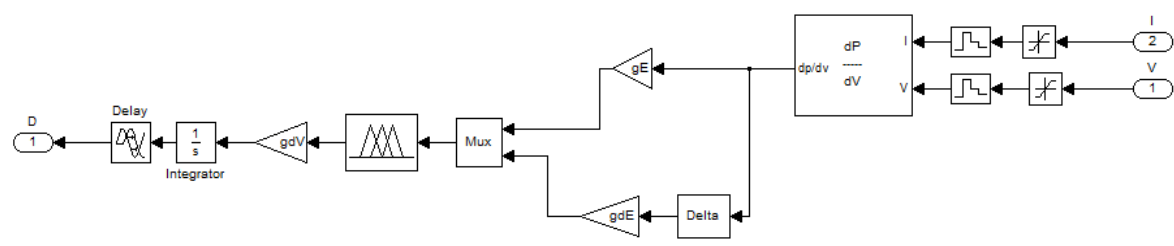

Figure 6. Global configuration of FLC

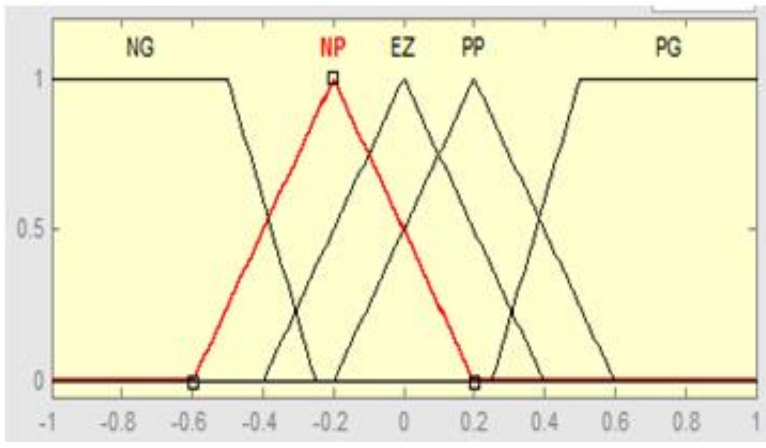

Figure 7. Input (E), (dE) and output (dD) membership functions for proposed FLC

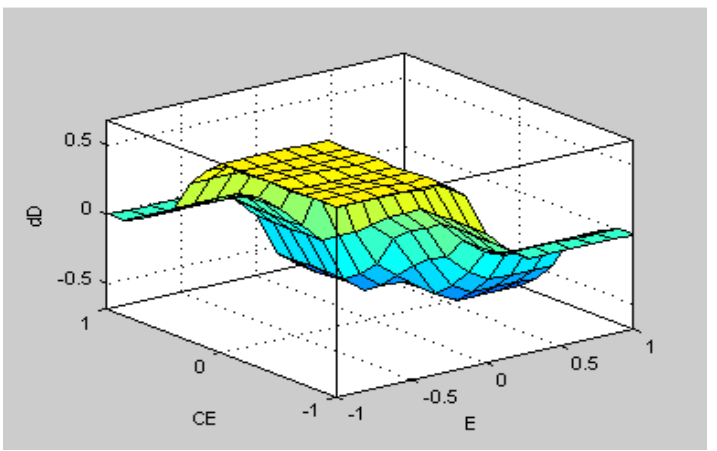

Figure 8. Characteristic surface of the FLC command

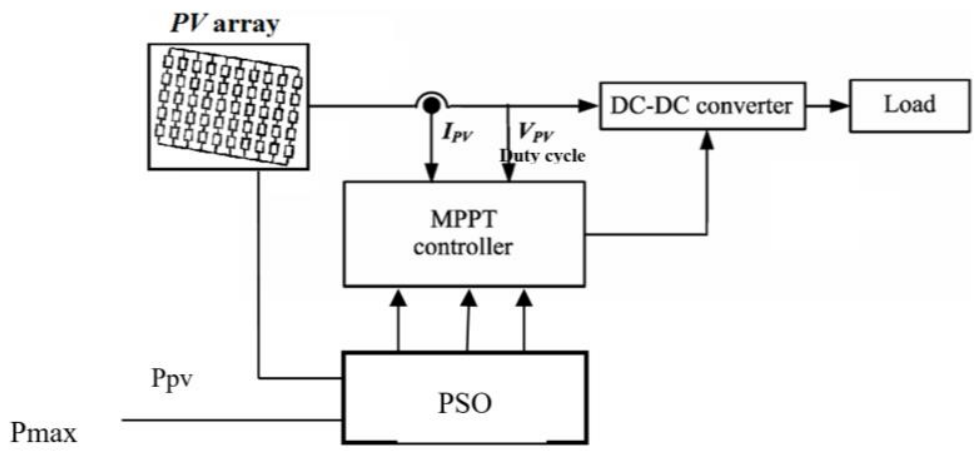

Figure 9. A fuzzy MPPT optimization approach 
The FLC command depends heavily and necessarily on the correct selection of certain design parameters namely input gains and output gain to improve the performances of the structure of the FLC method. To guide us in searching for the appropriate gains for the FLC controller, we used the particle swarm optimization method to optimize the parameters of the belonging functions associated with the input and exit variables. The idea is to optimize our maximum power delivered by the GPV in this case GMP inserting the command FLC by using a PSO program for the research of the appropriate gains of the FLC applied to the pursuit of the MPP. PSO as one of meta-heuristic optimization techniques depends on searching the optimal solution within the search area based on the exchange of experiences among particles in the population. The particles in the swarm modify their positions in the next iteration based on individual local best position and global best position of swarm. Each particle represents a solution for the control variables of the entire optimization problem [32]. PSO is used to optimize the gains of FLC algorithm which optimize the power output from PV array (MPPT) [33]-[35]. The proposed system simulated in MATLAB environment. To this end a 'fuzzy _optmize_PSOMATLAB' program has been designed for the search for the gains of the FLC. The appropriate gains for this optimization approach by running this PSO program as presented in Table 3 .

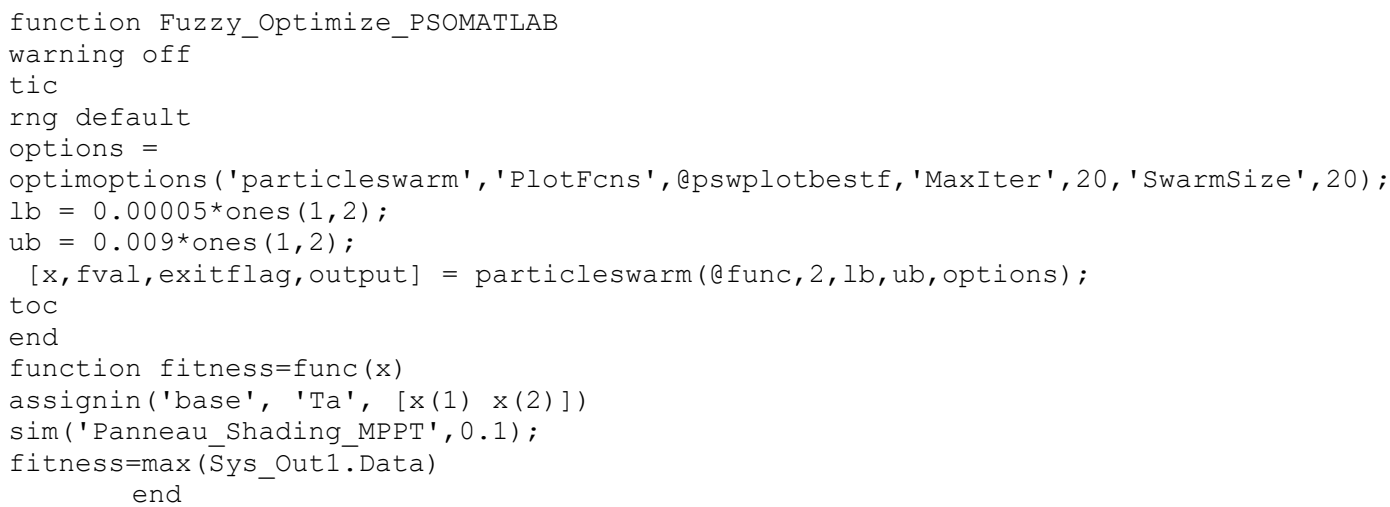

Table 3. The performance of FLC

\begin{tabular}{ll}
\hline Variable & Values \\
\hline $\mathrm{gE}$ & 0.001 \\
$\mathrm{gdE}$ & 0.0001 \\
$\mathrm{gdV}$ & 3900 \\
\hline
\end{tabular}

\section{COMPARATIVE SIMULATION RESULTS AND ANALYSIS}

In this FLC method the presence of partial shading is achieved by a power variation of $\pm 100 \mathrm{~W}$. The proposed solution for GMP research is to scan the speech universe [0 1] of the duty cycle by making an extension of the values of the FLC parameters while saving the maximum value of the power obtained in the process. This will allow us to detect the real GMP. A MATLAB program has been developed to simulate the implementation of the method proposed to the MPPT controlled GPV system in Figure 10 as part of partial shading. To test the FLC algorithm, the search for GMP was simulated using a GPV (10x10). The GPV is uniformly insolated at first, before the shading configuration of Figure 1 occurs at $\mathrm{t}=1 \mathrm{~s}$ with a shading level of $\mathrm{G}=100 \mathrm{~W} / \mathrm{m}^{2}$.

Figure 11 (a) and Figure 11 (b) shows the simulation results. When shading occurs, it appears that the power generated by the GPV evolves along the stabilizing PV characteristic at the GMP namely $3208 \mathrm{~W}$, that the classical algorithm 'P\&O' does not arrive to follow him in Figure 11 (a). The Figure 11 (b) shows us the ability of the FLC to track down the global power point that is $3208 \mathrm{~W}$ that the classical 'P\&O' algorithm can't track it. It should be noted, however, that ripples appear during the simulation by the FLC command but less important compared to those produced by the 'P\&O' algorithm. Any attempt to delineate these ripples by changing the earnings values of our FLC controller leads us to move away from the global power point and thus to cause losses. The adjustment of the parameters (gains) of the FLC controller by the PSO algorithm allowed us to avoid a work of searching for gains by tweaking that can take a lot of time. 


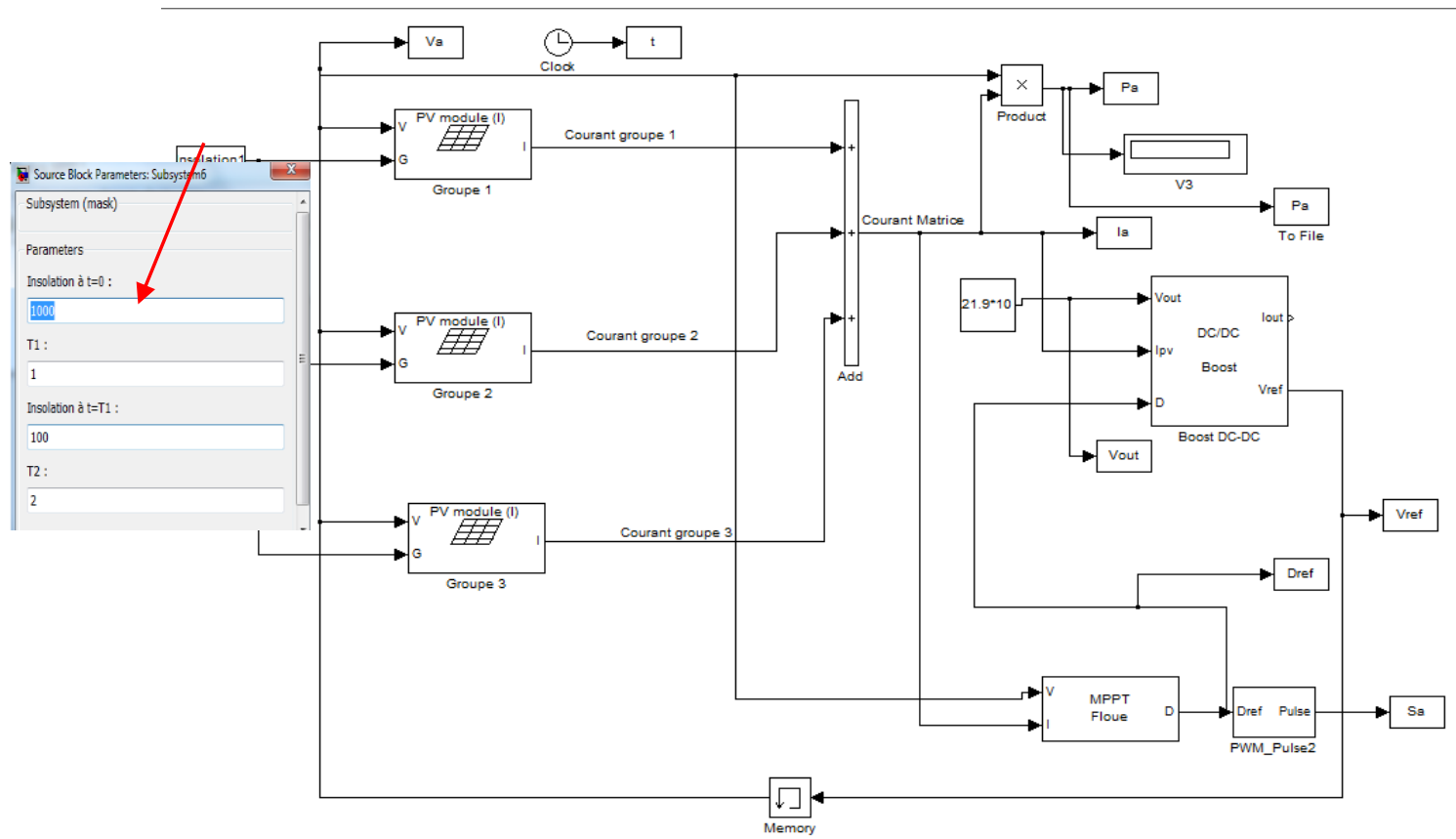

Figure 10. Bloc simulink of the GPV under partial shading with MPPT methods

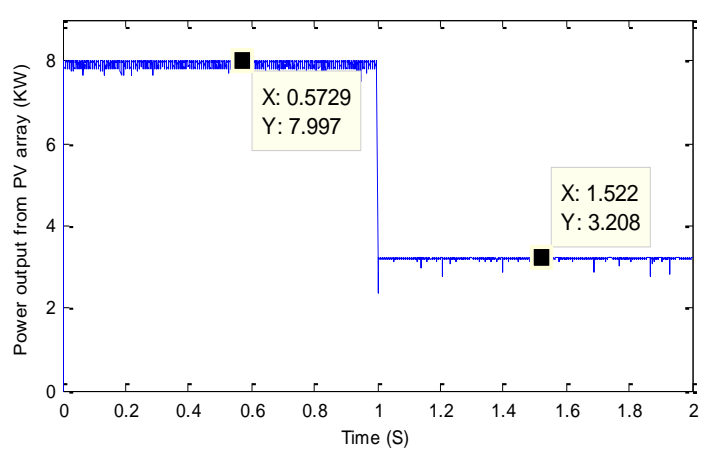

(a)

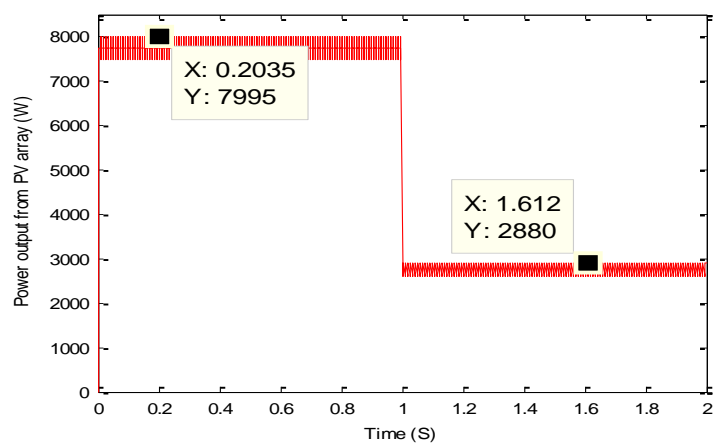

(b)

Figure 11. Curve of $\mathrm{P}(\mathrm{t})$ with variation of $\mathrm{G}\left(1000 \mathrm{~W} / \mathrm{m}^{2}\right.$ for $\left.100 \mathrm{~W} / \mathrm{m}^{2}\right)$ of Figure 1 with, (a) 'P\&O' and (b) FLC

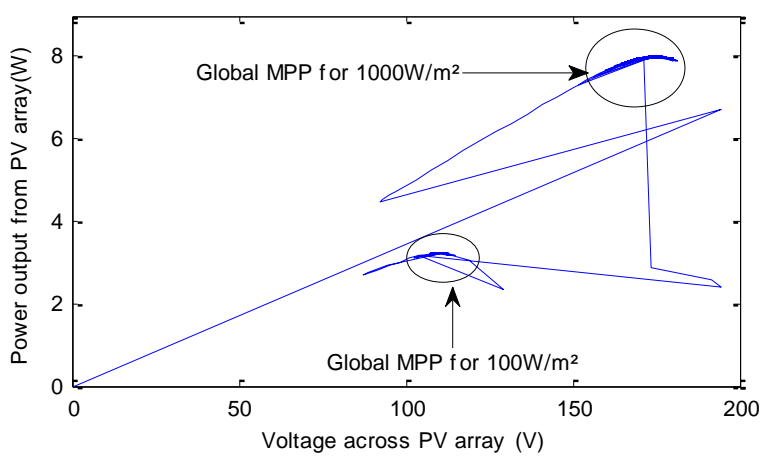

Figure 12. FLC tracking process from a uniform standard irradiation to the partial shading configuration of Figure 1 with a shading level of $0.1 \mathrm{~kW} / \mathrm{m}^{2}$ 


\section{CONCLUSION}

In this article, we show the inability of the classical 'P\&O' algorithm to track the overall power point for $<200 \mathrm{~W} / \mathrm{m} 2$ values causing losses for a GVP in the presence of partial shading. We then proposed an optimization approach to a fuzzy logic MPPT command that moves the operating point imposed by the partial shading configuration to a point near the global. The results showed a perfect ability of the proposed algorithm to track the overall MPP for the shading configuration of Figure 1 for a low level of irradiation. Finally, these results lead us to say that the proposed FLC control method can solve the overall problem of tracking MPs with the classical 'P\&O' algorithm.

\section{APPENDIX}

Table 4. PV module manufacturer's data

\begin{tabular}{ll}
\hline Parameters & vakue \\
\hline Open circuit voltage $V_{o c}$ & $21.9 \mathrm{~V}$ \\
Short-circuit current $I_{s c}$ & $4.95 \mathrm{~A}$ \\
Optimal voltage $V_{m}$ & $17.5 \mathrm{~V}$ \\
Optimal current $I_{m}$ & $4.57 \mathrm{~A}$ \\
Maximal power $P_{m}$ & $80 \mathrm{~W}$ \\
Series resistance $R_{s}$ at $T_{s t c}$ & $0.0102 \Omega$ \\
\hline
\end{tabular}

\section{REFERENCES}

[1] Dezso Sera, Laszlo Mathe, Tamas Kerekes, Sergiu Spataru and Remus Teodorescu, "On the parturb-and-observe and Inc.Cond MPPT methods for PV systems," IEEE Journal of Photovoltaics, vol. 3, no. 3, pp. 1070-1078, 2013, DOI: 10.1109/Jphotov.2013.2261118

[2] T.-Y. Kim, H.-G. Ahn, S. K. Park, and Y.-K. Lee, "A novel MPPT control for photovoltaic power system under rapidly changing solar radiation," IEEE Int. Symp. Ind. Electron., 2001, pp. 1011-014, DOI: 10.1109/ISIE.2001.931613

[3] Liu X., and Lopes L.A.C., "An improved 'P\&O' MPPT algorithm for PV arrays," Conf. Rec. PESC'04, Aachen, Germany, June 2004, pp. 2005-2010, DOI: 10.1109/PESC.2004.1355425

[4] Liu C., Wu B., and Cheung R., "Advanced algorithm for MPPT control of photovoltaic systems," Conf. Rec. of the first Canadian Solar Buildings Conference, Montreal, August 2004.

[5] Femia, G. Petrone, G. Spagnuolo, and M. Vitelli, "Optimization of 'P\&O' MPPT method," IEEE Trans. Power Electron., vol. 20, no. 4, pp. 963-973, Jul. 2005, DOI: 10.1109/TPEL.2005.850975

[6] W. Xiao, J. Lind, W. Dunford, and A Capel, "Real-time identification of optimal operating points in photovoltaic power systems," IEEE Transactions on Industrial Electronics, vol. 53, no. 4, pp. 1017-1026, August 2006, DOI: 10.1109/TIE.2006.878355

[7] J. C. Hernández, O. G. Garcia and Francisco Jurado, "Photovoltaic devices under partial shading conditions," International Review on Modelling and Simulations, vol. 5, no. 1, pp. 414-425, 2012.

[8] R. Ramaprabha and Dr.B.L. Mathur, "Comparative study of series and parallel configurations of solar PV array under partial shaded conditions," International Review on Modelling and Simulations (IREMOS), vol. 3, no. 6, pp. 1363-1371.

[9] M. Mostefai, A. Miloudi and Y. Miloud, "An intelligent MPPT for photovoltaic systems based on neural network," International Review on Modelling and Simulations (IREMOS), vol. 6, no. 5, October 2013

[10] K. H. Hussein and I. Muta, "MPPT: An algorithm for rapidly changing atmospheric conditions," Proc. Inst. Electr. Eng. Gener., Transmiss. Distrib. vol. 142, no. 1, pp. 59-64, Jan. 1995.

[11] S. Jain and V. Agarwal, "A new algorithm for rapid tracking of approxi-mate MPP in photovoltaics systems," IEEE Power Electron. Lett., vol. 2, no. 1, pp. 16-19, Mar. 2004, DOI: 10.1109/LPEL.2004.828444

[12] L.A. Hecktheuer, A. Krenzinger, C.W.M. Prieb, "Methodology for photovoltaic modules characterization and shading effects analysis," Journal of the Brazilian Society of Mechanical Sciences, vol. 24, no. 1, pp. 26-32, 2002, DOI: 10.1590/S0100-73862002000100004

[13] K.S. Parlak and H. Can, "A new MPPT method for PV array system under partially shaded conditions," $20123 \mathrm{rd}$ IEEE International Symposium on Power Electronics for Distributed Generation Systems (PEDG), June 2012, pp. 437-441, DOI: 10.1109/PEDG.2012.6254039

[14] Mohamed Amine Abdourraziq and Mohamed Maaroufi, "Experimental verification of the main MPPT techniques for photovoltaic system," International Journal of Power Electronics and Drive Systems (IJPEDS), vol. 8, no. 1, pp. 384-391, 2017, DOI: 10.11591/ijpeds.v8.i1.pp384-391

[15] Yaichi, M., Fellah, M. K, and Mammeri, A, "A neural network based MPPT technique controller for photovoltaic pumping system," International Journal of Power Electronics and Drive Systems (IJPEDS), vol. 4, no. 2, pp. 241-255, 2014, DOI: 10.11591/ijpeds.v4i2.5875

[16] Ishaque, K and Salam, Z, "A review of MPPT techniques of PV system for uniform insolation and partial shading condition," Renew. Sustain. Energy Rev, vol. 19, pp. 475-488, 2013, DOI: /10.1016/j.rser.2012.11.032 
[17] H. Zheng, S. Li, R. Challoo and J. Proano, "Shading and bypass diode impacts to energy extraction of PV arrays under different converter configurations," Renewable Energy, vol. 68, pp. 58-66, 2014, DOI: 10.1016/j.renene.2014.01.025

[18] M. A. M. Ramli, S. Twaha, K. Ishaque and Y. A. Al-Turki, "A review on MPPT for photovoltaic systems with and without shading conditions," Renewable and Sustainable Energy Reviews, vol. 67, pp. 144-159, 2017, DOI: 10.1016/j.rser.2016.09.013

[19] K. Latha Shenoy, C. Gurudas Nayak and Rajashekar P Mandi, "Effect of partial shading in grid connected solar PV system with FL Controller," International Journal of Power Electronics and Drive Systems (IJPEDS), vol. 12, no. 1, pp. 431-440, 2021, DOI: 10.11591/ijpeds.v12.i1.pp431-440

[20] Liqun Liu, Xiaoli Meng and Chunxia Liu, "A review of MPPT methods of PV power system at uniform an partial shading," Renew. Sustain. Energy Rev., vol. 53, pp. 1500-1507, 2016, DOI: 10.1016/j.rser.2015.09.065

[21] T. Sudhakar Babu, N. Rajasekar and K. Sangeetha, "Modified particle swarm optimization technique based MPPT for uniform and under partial shading condition," Appl. Soft Comput. J., vol. 34, pp. 613-624, 2015, DOI:

[22] Kadhim Hamzah Chalok and Mohammad Faridun Naim Tajuddin, "Optimal extraction of photovoltaic energy using FLC for MPPT technique," International Journal of Power Electronics and Drive Systems (IJPEDS), vol. 11, no. 3, pp. 1628-1639, September 2020, DOI: 10.11591/ijpeds.v11.i3.1628-1639

[23] Dadjé, Abdouramani, et al. "MPPT methods for photovoltaic systems operating under partially shaded or rapidly variable insolation conditions: a review paper," International Journal of Sustainable Engineering, vol. 9, no. 4, pp. 224-239, 2016.

[24] Mohammad Syahir Bin Ishak, Rahmatul Hidayah Salimin, Ismail Musirin and Zulkiffli Abdul Hamid, "Development of PV array configuration under different partial shading condition," International Journal of Power Electronics and Drive Systems (IJPEDS), vol. 10, no. 3, pp. 1263-1269, Sep 2019, DOI: 10.11591/ijpeds.v10.i3.pp1263-1269

[25] Youcef and A. Miloudi, "Optimization of partially shaded PV array using a modified P\&O MPPT algorithm," Leonardo Electronic Journal of Practices and Technologies, vol. 15, no. 28, pp. 179-196.

[26] H. Patel and V. Agarwal, "MATLAB-based modeling to study the effects of partial shading on PV Array Characteristics," IEEE Trans. on Energy Conversion, vol. 23, no. 1, pp. 302-310, Mar 2008, DOI: 10.1109/TEC.2007.914308

[27] Adel Haddouche, Mohammed Kara and Lotfi Farah, "MPPT using FLC with reduced rules," International Journal of Power Electronics and Drive Systems (IJPEDS), vol. 9, no. 3, pp. 1381-1390, Sep 2018

[28] Ahmad Saudi Samosir, Herri Gusmedi, Sri Purwiyanti and Endah Komalasari, "Modeling and Simulation of FLC based MPPT for PV Application," International Journal of Electrical and Computer Engineering (IJECE), vol. 8, no. 3, p. 1315-1323, 2018, DOI: 10.11591/ijece.v8i3.pp1315-1323

[29] Boualem Boukezata, Abdelmadjid Chaoui, Jean-Paul Gaubert and Mabrouk Hachemi, "An improved FLC MPPT based P\&O method to solve fast irradiation change problem," J. Renew. Sustain. Energy, vol. 8, no. 4, 2016, DOI: $10.1063 / 1.4960409$

[30] Masafumi Miyatake, Mummadi Veerachary, Fuhito Toriumi, Nobuhiko Fujii and Hideyoshi Ko, "MPPT of Multiple Photovoltaic Arrays: A PSO Approach," IEEE Transactions on Aerospace and Electronic Systems, vol. 47, no. 1, pp. 367-380, 2011, DOI: 10.1109/TAES.2011.5705681

[31] Yasser Ahmed and Ayman Hoballah, "Adaptive filter-FLC integration for torque ripples minimization in PMSM using PSO," International Journal of Power Electronics and Drive Systems (IJPEDS), vol. 10, no. 1, pp. 48-57, 2019, DOI: 10.11591/ijpeds.v10.i1.pp48-57

[32] Ayman Hoballah and Istvan Erlich, "PSO-ANN approach for transient stability constrained economic power generation," IEEE Bucharest Power Tech, Bucharest, 2009, pp. 1-6, DOI: 10.1109/PTC.2009.5281926

[33] Yen-Shin Lai and Juo-Chiun Lin, "New hybrid fuzzy controller for direct torque control induction motor drives," IEEE Transactions on Power Electronics, vol. 18, no. 5, pp. 1211-1219, 2003, DOI: 10.1109/TPEL.2003.816193

[34] Kashif Ishaque, Zainal Salam, Muhammad Amjad, and Saad Mekhilef, "An Improved PSO-Based MPPT for PV with Reduced Steady-State Oscillation," IEEE Transactions on Power Electronics, vol. 27, no. 8, pp. 362733638, 2012, DOI: 10.1109/TPEL.2012.2185713

[35] K. Sundareswarana, V. Vignesh Kumara and S. Palanib, "Application of a combined PSO and perturb and observe method for MPPT in PV systems under partial shading conditions," Renewable Energy, vol.75, March 2015, DOI: $10.1016 /$ j.renene.2014.09.044 